\title{
THE INTERNAL ENVIRONMENT AND BASIC REQUIREMENT Policy on the Performance of Retirement homes
}

\author{
K. Sarojani Krishnan *
}

\begin{abstract}
UniKL Business School
Universiti Kuala Lumpur Malaysia

ksarojani@unikl.edu.my
\end{abstract}

Nazatul Shima Abdul Rani

UniKL Business School

Universiti Kuala Lumpur

Malaysia

shima.rani@unikl.edu.my

*Corresponding Author email: ksarojani@unikl.edu.my 


\section{A B S T R A C T}

This study aims to examine the relationships between the internal environment (IERH), basic requirement policy (PRRH), and the performance of retirement homes (PRH). 205 out of 400 questionnaires returned and used for the study. The three variables under study were IERH ( 8 items), the PRRH (6 items), and PRH (8 items). Reliability analysis was run and all three variables showed high Cronbach Alpha values ranging from 0.83 to 0.87 thus indicating high reliability. The findings of the Pearson Correlation analysis suggested that the relationship between IERH and $\mathrm{PRH}$ is $r=0.80^{* *}$; $p=0.00$, while the relationship between the $\mathrm{PRRH}$ and $\mathrm{PRH}$ is $r=0.63^{* *} ; \mathrm{p}=0.00$. The findings suggested that there was a positive and significant relationship between $\mathrm{PRH}$ with IERH and PRRH. IERH had a strong positive relationship with the $\mathrm{PRH}$. In terms of the relationship between IERH and $\mathrm{PRRH}$, there was a positive and a moderate relationship $\left(r=0.54^{* *} ; \mathrm{p}=0.00\right)$. Hence, in order to promote good performance, a RH must ensure that the IERH either meets or exceeds the expectations of the tenants and fulfils the basic requirements of $\mathrm{PRRH}$.

Keywords: Retirement, Homes, Performance, Policy, Internal Environment

\section{R E S E A R C H H I G H L I G H T S}

There was a direct and significant relationship concerning PRRH, IERH and PRH. Hence, all three hypotheses are accepted.

Five critical elements included under IERH were elderly centric treatment by professionals, the relationship between elderly and professionals from the hospital, events to remain the elderly happy, fit, and active, 24-hour professional and ambulance service, and an integrated database system for health, treatment, etc.

The PRRH consists of government collaboration with NGOs in providing transport and medical assistance, integration of the multipurpose intelligent card for public transport and grocery shopping, food bank supply in collaboration with social volunteers, a publicly accessible and integrated database, and effective and efficient activity space management.

The PRH can be measured by the increasing number of new check-ins and retained elderly, quality of food and facilities, health screening equipment, caretaker skills in creating activities, and internet connection.

\section{G R A P H I C A L A B S T R A C T}

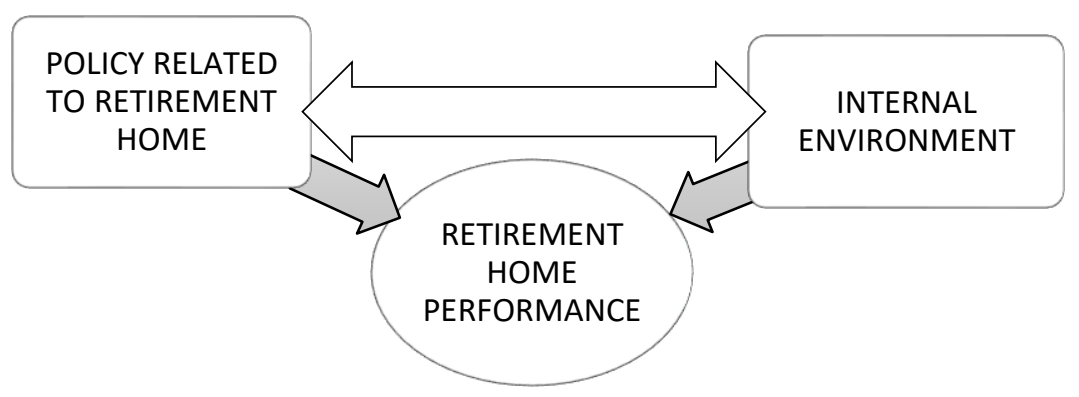

Fig. 1. Relationship between Policy, Internal Environment and Retirement Home Performance 


\section{Research Objectives}

ROI: To determine the relationship between IERH, PRRH and $\mathrm{PRH}$,

RO2: To determine the relationship between $\mathrm{PRRH}$ and the IERH.

RO3: To identify the elements critical for IERH, PRRH and PRH.

This study concentrated the critical elements for the IERH, the PRRH and the PRH.

The findings of this study have implications to improve private as well as government retirement homes in terms of the IERH, PPRH, and $\mathrm{PRH}$.

\section{Methodology}

The research instrument is questionnaire for data collection. It is divided into two parts: Part $A$ is on respondent profile, and Part $B$ is on the three variables which include $P R R H, I E R H$ and $\mathrm{PRH}$.

About 400 questionnaires were distributed to several retirement homes in Kuala Lumpur (100), Selangor (100), Johor (100), and Kelantan (100). A total of 210 questionnaires was returned, with 205 uses for the analysis. The method used was dropped and collect, whereby the questionnaires were sent to the retirement homes and collected over two weeks. The respondent's participation in the survey was voluntary.

Out of 205 respondents, 51.2\% were males while $48.8 \%$ were female respondents. In terms of racial breakdown, 58.5\% were Malays, 35.1\% Chinese, and $6.3 \%$ Indians. About 38\% of them were 44 to 55 years old, $52.7 \%$ were aged between 56 and 70 years old, and $9.3 \%$ of the respondents were over 70 years old. In terms of location, $41 \%$ respondents hailed from Selangor, 24.9\% from Kelantan, 21\% from Johor, and 13.2\% from Kuala Lumpur.

Reliability analysis revealed that the reliability was above average of Cronbach's Alpha scores for PRH ( $\alpha=0.88,8$ items), PRRH homes ( $\alpha=0.86,6$ items), and IERH ( $\alpha=0.83,8$ items).

\section{Results}

Pearson Correlation analysis, among the three variables under study. The three variables include PRRH with a mean of 3.79 and standard deviation of 0.72 , followed by PRH with a mean of 3.55, and standard deviation of 0.62, and IERH with a mean of 3.51 and standard deviation of 0.60 .

The results indicated a very solid relationship between PRH and IERH ( $\left.r=0.80^{* *} ; p=0.000\right)$, while there was a moderate relationship between PRH and PPRH $\left(r=0.63^{* *} ; p=0.000\right)$. Furthermore, the correlation between IERH and PPRH was moderate $\left(r=0.54^{* *} ; p=0.000\right)$. As such, $\mathrm{H} 1, \mathrm{H} 2$, and $\mathrm{H} 3$ are accepted.

\section{Findings}

The findings of the research were similar to previous studies indicating that PRRH and IERH are critical for the PRH. The IERH includes elements such as elderly centric treatment, the 
relationship between the elderly and professionals from hospitals, activities, and 24-hour professional ambulance service (Tyvimaa, 2011). The important elements for PRRH on the other hand, comprise collaboration with NGOs for transport and medical assistance, the multipurpose intelligent card for the elderly, and foodbank supply (Shaw, Rosen, \& Rumbold, 2011). On the other hand, the important elements included under the concept of $\mathrm{PRH}$ consist of the increasing number of new check-ins and retained elderly, quality of food and facilities, and health screening equipment.

\section{Acknowledgement}

We would like to express our appreciation to Universiti Kuala Lumpur to fund this research under Short Term Research Grant funding with Reference Code: UniKL/CoRI/STR18029.

\section{References}

Shaw, S., Rosen, R., \& Rumbold, B. (2011). An overview of integrated care in the NHS. What is integrated care. London: Nuffield Trust.

Tyvimaa, T. (2011), Social and physical environments in senior communities: the Finnish experience, International Journal of Housing Markets and Analysis, 4(3), 197-209. https://doi.org/10.1108/17538271111152997.

\section{Author's Biography}

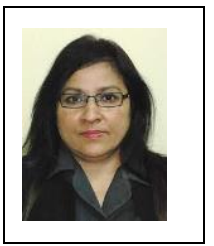

Dr K. Sarojani Krishnan is currently a Senior Lecturer at Universiti Kuala Lumpur Business School, UniKL. She has more than 20 years' of teaching experience at the university. Her areas of research interest include language testing and evaluation, assessment, language performance, teaching and learning, motivation and demotivation, entrepreneurship and leadership.

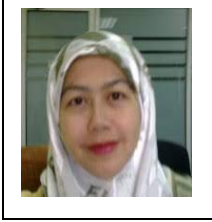

Dr. Nazatul Shima Abdul Rani is a Senior Lecturer in UniKL Business School, Universiti Kuala Lumpur. Her areas of expertise include management, strategic management, organizational behaviour, entrepreneurship, small business management, and other related business field. She has 2 years' of industry experience and more than 20 years in higher education industry. 